\section{Approximate Model for Examination of Cone Dispenser Eccentricity}

\author{
Zoltán Hagymássy \\ University of Debrecen, Centre for Agricultural Sciences, \\ Faculty of Agricultural Sciences, \\ Department of Mechanics, Debrecen \\ hagymassy@helios.date.hu
}

\section{SUMMARY}

The most important distributing construction of small plot seed-drills, fertiliser dispensers is the cone dispenser. The cone dispenser can operate based on simple gravity or with Oyjord-type cone-cell or Hege-type cone-belt structure. The unevenness of spreading of each type is significantly influenced by the feeding roll above the cone and the misalignment of the cone dispenser. On designing, preparing and setting I realised that this job could be done much faster and more precisely if there would be model for testing the misalignment of the cone dispenser. In my article I will provide information about the essence of the mathematical model and its derivations. For the calculations I prepared a chart program in Microsoft Excel.

In order to test the computed model I made experimental examinations. I put together a test bench for the measurements. I revealed that the mathematical model describes the unevenness of spreading caused by misalignment. In addition, I discovered that even a misalignment of 0.25-0.5 $\mathrm{mm}$ can be pointed out by measurements and is in proportion to the variety factor determined theoretically.

Keywords: plot fertilizer, cone dispenser, eccentricity, mathematical model

\section{INTRODUCTION, LITERATURE}

The Oyjord-type cone-cell dispenser is mainly used on plot seed-drills, but every kind of grainy material can be distributed with it. This solution meant essential change compared to the previous principles (Betzwar, 1992). Setting of desired dosage became possible by it as the specified amount of grain can be distributed precisely on determined size of plot without any remainder, without the risk of mixing the grains allotted to different plots while the machine is continuously driving along the plots (Hege, 1986).

The cone-belt dispenser has been used widely since the 1980s mainly on plot seed-drills and some plot fertiliser distributors (Rödel, 1984). According to Hege (1987) it distributes micrograins and fertiliser quite precisely.

Zhizhong et al. (1994) says eccentricity is an important factor, which increases unevenness of spreading at cone dispensers. The feeding funnel and the midline of the roll connected to it must exactly concur with the midline of the cone dispenser. The even distribution of the grains can be guaranteed only this way.

\section{MATERIAL AND METHOD}

\section{Introducing the conditions of development and examinations}

The jobs of design, development, execution and examinations were carried out at the EducationResearch Base of University of Debrecen, Centre for Agricultural Sciences, Faculty of Agricultural Sciences, Department of Mechanics.

The following fertilisers were used during my tests:

- NPK 15-15-15 (Agrolinz Agrotechnikalien $\mathrm{GmbH})$

- Salt of Linz (ammonium nitrate limestone 27\% N, Agrolinz Melanin $\mathrm{GmbH}$ )

- Potash (0-0-60\%, Tiszamenti Vegyimüvek, Szolnok)

- Ammonium nitrate (34\% N, Nitrogénmüvek Rt., Pétfürdő)

\section{Improvement of the cone-dispenser}

I designed and prepared a cone dispenser operating based on gravity which works as the followings:

The amount of fertiliser measured in advance precisely is poured into the mouth (1) and the feeding roll connected to it (3). By turning the adjustment lever (2) the pod (5) raises the feeding roll by $30 \mathrm{~mm}$ moving curvilinearly. The fertiliser flowing down the cone dispenser (7) spreads on eight leading pipe (8). The advantage of this device is that it is senseless to the size of the grain, it is able to distribute precisely any kind of fertiliser with mixed agents and grain structure in small amount as well (Figure 1).

Figure 1: Draft of the gravity cone dispenser

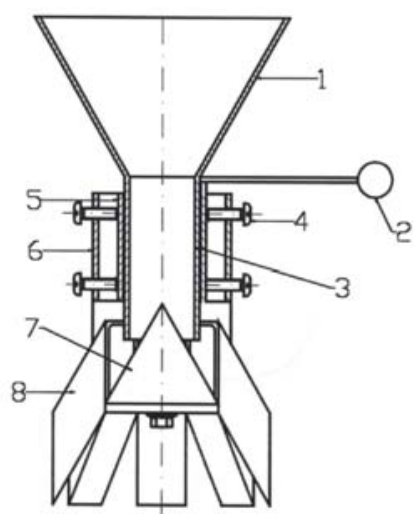


Test bench for the examination of the cone dispenser

I prepared a test bench for the examination of eccentricity between the cone dispenser and the feeding roll (Figure 2). An interceptor can be placed under each of the eight output pipe of the cone dispenser. The weight of the collected fertiliser was measured with a digital scale of $0.1 \mathrm{~g}$ accuracy.

Figure 2: Test bench for checking gravity cone dispenser

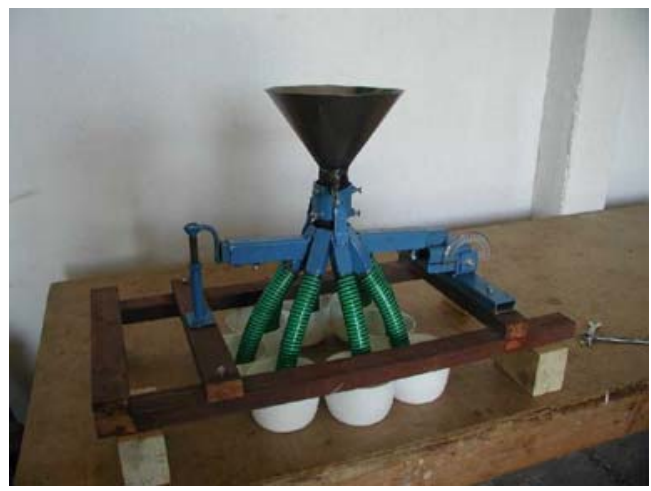

I set the frame structure of the test bench aclinally with level. The alignment of the feeding roll and the cone dispenser was adjusted by six $M 8 \times 1 \mathrm{~mm}$ adjuster bolts. The fertiliser flown out of each segment was weighed with the four types of fertilisers. The pitch of the M 8x1 mm adjuster bolts is $1 \mathrm{~mm}$, therefore I could set $0.25 \mathrm{~mm}$ eccentricity by driving $1 / 4$ turn on the two adjuster bolts above each other on one side, easing the bolts opposite them. Then I made measurements with 4 types of fertilisers by adjusting the bolts at $1 / 4$ turns. The adjusted values of the eccentricity: $0.25 \mathrm{~mm} ; 0.5$ $\mathrm{mm} ; 0.75 \mathrm{~mm} ; 1 \mathrm{~mm}$.

One of the most essential interrelation for determining the unevenness of spreading is the variety factor (Csizmazia, 1993).

$$
C V=\frac{100}{\bar{x}} \sqrt{\frac{\sum_{i=1}^{n}\left(x_{i}-\bar{x}\right)^{2}}{n-1}}
$$

Where:

$x_{i}$ - the average amount of collected fertiliser at a certain test place during three measurements

$\bar{x}-$ the average amount of collected fertiliser at all test places during three measurements $n$ - the number of test places

\section{RESULTS AND EVALUATION}

\section{Approximate model for examination of cone dispenser and feeding roll eccentricity}

Firstly I examined how the grains empty from the cone dispenser if the cone dispenser and the feeding roll are aligned. By raising the feeding roll at „h” extent the grains leave through the gap between the bottom edge of the roll and the cone lateral face (Figure 1). The measures of the horizontal elevation of the transfusion hole: outer diameter „d", inner diameter: „ $\mathrm{d}_{1}$ ”. In the case of eight output pipes by dividing the transfusion hole into eight parts, the surface of one sector segment $\left(T_{1}\right)$ is in proportion to the weight of fertiliser leaving the output pipe.

The essence of my theory: even if the feeding roll and the cone dispenser are not aligned, the territories of the theoretical sector segments (T1...T8) are in proportion to the amount of the fertiliser leaving the output pipes (Figure 3). The calculation of different sector segment territories (T1...T8) is only mathematical problem.

\section{Figure 3: Comparison of the sector segments of the gap between the aligned or eccentric cone dispenser and feeding roll}
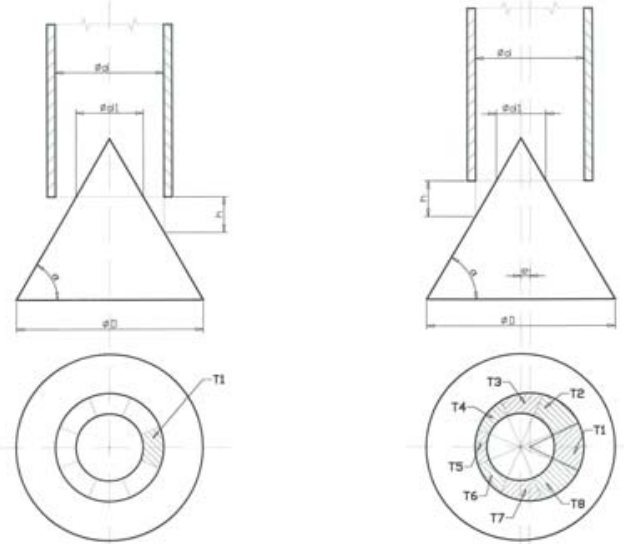

The calculation process briefly, with the help of draft (Figure 4):

The horizontal level bordered by the bottom edge of the feeding roll trims a circle out of the cone dispenser on the surface of the cone lateral face:

$$
d_{1}=2 \cdot\left[\frac{d}{2}-e-\left(h \cdot \operatorname{tg} \frac{\alpha}{2}\right)\right]
$$

$\lambda_{1}=22.5^{\mathrm{o}} ; \lambda_{2}=67.5^{\mathrm{o}} ; \lambda_{3}=112.5^{\mathrm{o}} ; \lambda_{4}=157.5^{\mathrm{o}}$ The marks can be found on Figure 4.

Figure 4: Geometric principle for calculating the territories of sector segments (T1...T8) in the case of eccentric feeding roll and cone dispenser

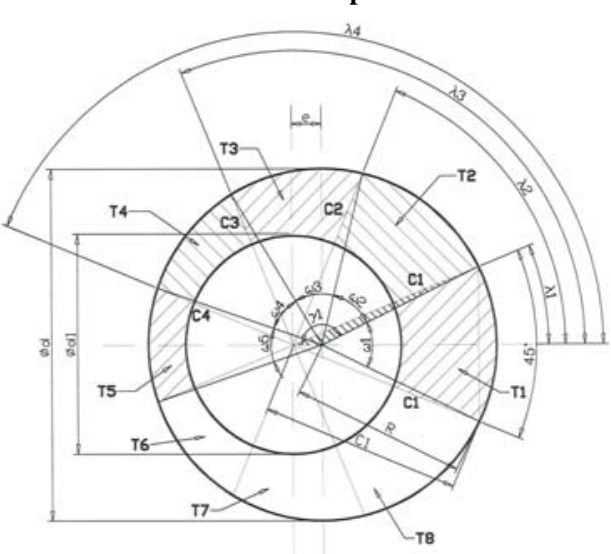


Due to the symmetry of the cone dispenser.

$T_{6}=T_{4}$
$T_{7}=T_{3}$
$T_{8}=T_{2}$

I consider the $T_{1} \ldots T_{8}$ sector segment territories to be in proportion to the amount of fertiliser collected at the eight output pipes of the cone dispenser.

Theoretical variety factors $(\mathrm{CV})$ were calculated from the given results in the case of different eccentricity values. For the calculation process a chart program was made in Microsoft Excel, in which the main dimensions of the cone dispenser can be changed.

Variants:

$\mathrm{d}$ - the inner diameter of the feeding roll

E- eccentricity

$\mathrm{H}$ - raising height of the feeding roll at opening

$\alpha$ - the cone angle of the cone dispenser

The effect of changing different geometrical measures on the unevenness of spreading caused by eccentricity can be modelled by changing the main dimensions.

\section{Comparison of the theoretical model and the eccentricity examination made on test benches}

The results of measuring the unevenness of spreading caused by eccentricity are included in (Figure 5) by using the diagram comparison evaluation is possible between the unevenness of spreading calculated by computer model „CV theoretical" and the test results of the four examined fertilisers.

- It can be declared that the theoretical model describes the unevenness caused by eccentricity well.

- Noticeable that the spreading of salt of Linz grains is less even in the output pipes. The explanation of this phenomenon - in my opinion - is that in the case of the large but smoothly rolling salt of Linz grains even if only some grains roll to another output pipe, it can significantly effect the unevenness of spreading.

- We can diagnose that even a misalignment of $0.25-0.5 \mathrm{~mm}$ cause change in the unevenness of spreading, which is in proportion to the theoretically determined variety factor.

Figure 5: Unevenness of spreading caused by eccentricity, the amount of $\mathbf{7 5}$ gram fertilizer

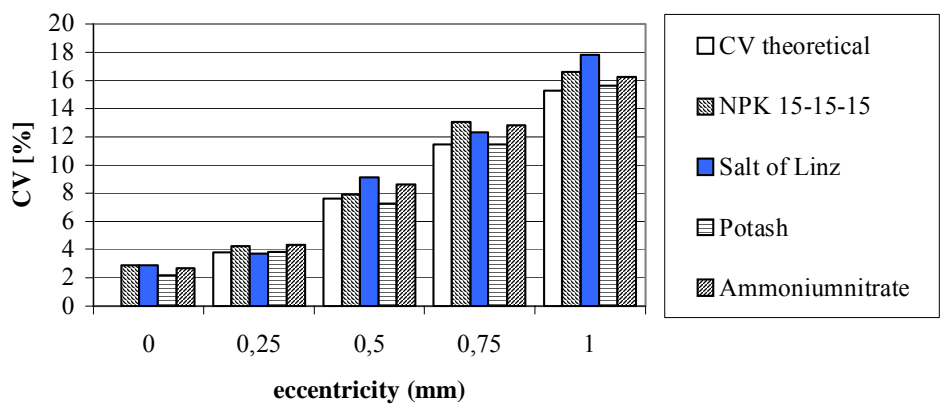

REFERENCES

Betzwar, W. (1992): A method for the evaluation of seed distribution of plot seeders and precision spaced planters. Proceedings of the Eight International Conference on Mechanisation of Field Experiments Soest, Germany, 68-82.

Csizmazia, Z. (1993): Technical Conditions of Equalized Fertilizer Applications. Hungarian Agricultural Research, 12. 16-22.

Hege, H. U. (1986): Planters and drills for research plots short survey of various systems. The IAMFE Journal and Newsletter, Norway, 1. 29-33.
Hege, H. U. (1987): Plot planting equipment of the Hege Company. Proceedings of the IAMFE/ICARDA Conference Heald at Aleppo/Syria, 48-54.

Rödel, G. (1984): The belt dispenser. Proceedings of the Sixth International Conference on Mechanisation of Field Experiments Dublin, Ireland, 106-113.

Zhizhong, Z.-Hongbo, S.-Xiuyu, W. (1994): The research on plot drill series. Proceedings of the Ninth International Conference on Mechanisation of Field Experiments Beijing, China, 168172 . 